\title{
Individual differences in cognitive plasticity: an investigation of training curves in younger and older adults
}

\author{
Céline N. Bürki - Catherine Ludwig • \\ Christian Chicherio $\cdot$ Anik de Ribaupierre
}

Received: 3 June 2013/Accepted: 26 February 2014/Published online: 21 March 2014

(C) Springer-Verlag Berlin Heidelberg 2014

\begin{abstract}
To date, cognitive intervention research has provided mixed but nevertheless promising evidence with respect to the effects of cognitive training on untrained tasks (transfer). However, the mechanisms behind learning, training effects and their predictors are not fully understood. Moreover, individual differences, which may constitute an important factor impacting training outcome, are usually neglected. We suggest investigating individual training performance across training sessions in order to gain finer-grained knowledge of training gains, on the one hand, and assessing the potential impact of predictors such as age and fluid intelligence on learning rate, on the other hand. To this aim, we propose to model individual learning curves to examine the intra-individual change in training as well as inter-individual differences in intra-individual
\end{abstract}

C. N. Bürki $(\square)$

Felix Platter-Hospital, University Center for Medicine of Aging Basel, Basel, Switzerland

e-mail: Celine.Buerki@usb.ch

\section{N. Bürki}

Division of Diagnostic and Interventional Neuroradiology, Department of Radiology, University of Basel Hospital, Petersgraben 4, 4031 Basel, Switzerland

\section{Ludwig}

School of Health - Geneva, University of Applied Sciences

Western Switzerland, Geneva, Switzerland

\section{Chicherio}

Neuropsychology Unit, Neurology Clinic, Department of Clinical Neurosciences, Geneva University Hospitals, Geneva, Switzerland

A. de Ribaupierre

Faculty of Psychology and Educational Sciences, University of Geneva, Geneva, Switzerland change. We recommend introducing a latent growth curve model (LGCM) analysis, a method frequently applied to learning data but rarely used in cognitive training research. Such advanced analyses of the training phase allow identifying factors to be respected when designing effective tailor-made training interventions. To illustrate the proposed approach, a LGCM analysis using data of a 10-day working memory training study in younger and older adults is reported.

\section{Introduction}

Complex cognitive abilities like memory, language and attention are used in virtually all daily activities and therefore play a central role in our everyday life. Consequently, healthy cognitive functioning constitutes a key ingredient for individual well-being and maintenance of autonomy, a central component of successful aging (Baltes and Baltes 1990; Willis et al. 1992). Advancing age, however, is normally accompanied by cognitive decline, which is observed in multiple cognitive domains, although not in all, including the aforementioned ones (e.g., Lövdén et al. 2004). Nowadays, much cognitive intervention research is realized with the aim of triggering generalization effects to untrained domains, with the hope to ultimately counteract cognitive decline. Efforts are especially made with regard to the older population, since gains in cognitive functioning may help older people to preserve independent living until a very old age.

In recent years, the concept of plasticity has become a widely used term in many fields of cognitive psychology and behavioral neuroscience. In the present work, we use the term cognitive plasticity and define it in a life span developmental view as the intra-individual modifiability of 
behavior and the potential for different forms of behavior to adapt to environmental demands (Baltes and Lindenberger 1988; de Ribaupierre et al. 2009; Willis et al. 2009). The life span developmental approach supports the view that human development is characterized by lifelong modifiability and adaptability, which varies among individuals and is probably linked to the resources available to them.

The study of cognitive plasticity by cognitive training is not a new approach, and the training of intellectual abilities has a long history, particularly in childhood and in older adulthood (e.g., Baltes et al. 1988; Schaie and Willis 1986; Willis et al. 1981). Over two decades ago, cognitive plasticity in older adults was studied in a systematic way in a seminal work by Baltes and Kliegl (1992; Baltes and Lindenberger 1988; Kliegl et al. 1989). The authors examined the limits of plasticity in episodic memory by teaching a mnemonic technique, the method of loci. Up to thirty-eight training sessions were provided in order to let the participants reach asymptote in performance and the limit in learning a list of 30 words. Results of this series of age-comparative plasticity studies showed that cognitive plasticity is preserved in older age but is nevertheless reduced, as compared to younger age. Additionally, age differences and inter-individual differences within agegroups were magnified after the training.

Central in the context of learning and training research is the concept of transfer (Hager and Hasselhorn 1998; Willis 2001). Transfer refers to the generalization of training effects to untrained tasks, in other words, to the extension of the newly acquired knowledge or abilities to new situations (Willis 2001; Willis and Schaie 2009). The concept of transfer has already been discussed in very early cognitive research where the interdependence of mental functions in relation to training was investigated (Thorndike and Woodworth 1901). Generally, two types of transfer are distinguished: near-transfer and far-transfer (Edwards et al. 2002; Willis et al. 1981). Near-transfer occurs when the abilities required by the transfer situation highly overlap with those in the training situation. Fartransfer qualifies a gain in tasks that share few cognitive processes with the trained task.

Recently, a set of studies drew attention to the efficiency of working memory (WM) training interventions and to their potential to bring transfer effects (Klingberg 2010; Perrig et al. 2009; Sternberg 2008). WM is considered to constitute a central cognitive process, or set of processes, used in all complex tasks. WM capacity is limited and increases/ decreases over the course of the life span and has been shown to lead to large individual differences in cognitive performance within age-groups (de Ribaupierre et al. 2011; Engle et al. 1999). WM training was found to induce near- and fartransfer effects in children (Klingberg et al. 2005; Klingberg et al. 2002), younger adults (Jaeggi et al. 2008, 2010; Olesen et al. 2004; Westerberg and Klingberg 2007) and older adults (Borella et al. 2010; Buschkuehl et al. 2008; Richmond et al. 2011). However, the pattern of transfer effects was not uniform across studies, and results are somewhat controversial (Redick et al. 2013; Shipstead et al. 2012). Near-transfer effects were not consistently reported across all administered tasks targeting WM (Jaeggi et al. 2008; Richmond et al. 2011) or seemed to be modality specific; for instance, transfer was only observed in the visuo-spatial domain but not in the verbal domain (Buschkuehl et al. 2008). In other studies, however, transfer effects were found in many tasks across a large range of cognitive domains from short-term memory, WM, processing speed, inhibition and fluid intelligence (Borella et al. 2010) to everyday attention (Richmond et al. 2011).

Only few studies directly compared WM plasticity between younger and older adults. Dahlin, Nyberg, Bäckman and Neely (Dahlin et al. 2008) reported a significant training gain (gain in the trained task) for both age-groups, although larger in younger adults than in older adults. Transfer effects were limited to younger adults who showed both near- and far-transfer effects. These results contradict another WM training study where both agegroups improved significantly in the trained tasks and presented similar near-transfer effects (Li et al. 2008). In the more recent COGITO study, younger and older adults were trained on twelve different tasks of WM, speed and episodic memory over 100 daily 1 -h sessions. With respect to the WM training tasks, findings revealed a near-transfer effect to WM tasks in both age-groups (Schmiedek et al. 2010). Far-transfer effects to fluid intelligence and episodic memory tasks were limited to younger adults. Again, a heterogeneous pattern of training effects has also been observed with regard to age differences.

Overall, WM training appears to have potential to exhibit near- and far-transfer in younger as well as in older adults. Still, older adults usually exhibit less training gains and transfer effects than younger adults. However, evidence for near- and far-transfer effects is neither robust nor consistent, which indicates that transfer may be task or modality specific or affected by other confounding effects. Given the mixed results and since the factors impacting transfer effects are still not fully understood, it has been proposed that training research should focus on the mechanisms predicting transfer effects (Redick et al. 2013; Shipstead et al. 2012). Such a predictor could be individual training improvement as discussed by Richmond and colleagues (Richmond et al. 2011), who reported an enhanced fartransfer effect when participants without improvement during training were removed from the analysis. Therefore, individual differences in training improvement predicted training outcome. However, the large individual differences in cognitive resources especially across older adults are 
often neglected in intervention research (Kliegel and Bürki 2012). The observed training effects might therefore be relatively small relative to the large individual differences in cognitive functioning (Hertzog et al. 2009). Training groups are very likely to be heterogeneous so that individual differences in cognitive resources may cover the true individual training outcome and therefore account for the mixed findings in training improvement and in transfer effects. Hence, it seems important to consider individual differences in cognitive resources as an important factor modulating training outcomes. Still, to date, only few studies directly addressed this issue. An exception is the study by Saczynski et al. (2002) where this issue was already addressed more than a decade ago. The authors investigated the predictors of individual training gain in reasoning, in older adults. Training gains in reasoning ability from pretest to posttest were larger for participants who showed an enhanced strategy use at posttest. Predictors of enhanced strategy use were higher education and younger age (64-70). The predictor younger age is in line with results from a recent study where predictors of WM training gain and transfer effects were investigated in older adults (Zinke et al. 2014). Findings revealed that younger age and lower performance at pretest were related to larger training gains, and younger age as well as larger training gains was related to larger transfer effects. Another work also showed that only low performers at pretest improved in the trained tasks (Zinke et al. 2012). These findings are partially in line with the results of the speed of processing training data by Ball and colleagues from the ACTIVE study trial (Ball et al. 2007). They reported that deficits in speed of processing at pretest led to larger training gains, but no effect was found for demographic variables such as age and education. In a more recent paper from the ACTIVE study trial, inductive reasoning performance emerged as the best predictor of initial everyday functioning and the composite memory score of verbal episodic memory and everyday memory performance was the best predictor of changes in everyday functioning over time (Gross et al. 2011). The individual trajectories of everyday functioning performance over the measurements occasions during the training regimen were therefore predicted by individual differences in memory performance. Bissig and Lustig (2007) report individual differences in episodic memory training. They observed individual differences during encoding and were able to figure out the best strategy to use which leads to more training gains. Such findings empirically demonstrate that age and individual differences in cognitive resources or in strategy use impact training outcomes and that they need to be considered to enhance the efficiency of training regimen.

Most studies on training, whether focusing on group or on individual differences, focus on mean change from pretest to posttest performance or from the first to the last training session. We suggest analyzing the rate of learning across all the training sessions. Individual differences in these learning curves may provide valuable information about individual differences in plasticity and consequently, in the benefits of training gains. Such an approach was used in short-term learning and allowed the investigation of individual differences in learning rates and its predictors (Jones et al. 2005; Ram et al. 2005; Rast 2011). A recent work implemented a latent growth curve approach to assess changes in personality traits during a cognitive training intervention (Jackson et al. 2012). The findings revealed that cognitive training increased openness to experience over the course of the training intervention. Also individual differences in episodic memory plasticity were investigated by a latent curve analysis in a life span sample (Lövdén et al. 2012). Age-group differences and between-person differences were found to be increased as a function of training, and baseline performance and cognitive abilities tended to be positively associated with training gains. These studies demonstrate that a latent curve analysis approach may lead to a more fine-grained understanding of individual differences in learning and cognitive plasticity. To this day, however, too little research has been conducted on how individuals progress over cognitive training sessions and how that progression might be related to transfer effects. In other words, research has primarily focused on the results of training rather than on the training progression itself.

The aim of the present work was to use latent growth curve modeling (LCGM) to examine the relation between the growth of individual performance across training sessions and the amount of WM training benefits. By considering the starting point of the training (intercept) as well as the training curve over all training sessions (slope) for each individual, LGCM allows examining intra-individual change in learning over time as well as inter-individual differences in intraindividual change (Preacher et al. 2008). The focus is not on mean change as in traditional analyses of variance but on the analysis of individual trajectories (Voelkle 2007). The individual differences shift into the center of interest while in traditional analyses, individual differences are considered as error variance (Duncan and Duncan 2009). LGCM analysis also provides information about model fit, that is, whether the model describes the data well or not. LGCM analysis does further allow including predictors or covariates of change into the model and thus building a larger model of connections between growth and other variables (Muthén 1991). By testing conditional models, LGCM considers the influence of specific predictors on intercept and slope, such as age or a cognitive process. Doing so, the procedure allows disentangling differential effects of the predictors on intercept and slope. Finally, intercept and slope values can be linked to transfer scores providing a way to estimate the effect of individual differences on transfer effects. 
Table 1 Sample characteristics

Health scores reflect average response to seven questions on a scale from $1=$ excellent health to $5=$ very bad health.

$G c$ crystallized intelligence (Mill Hill Vocabulary Scale, see text), Gc scores represent total correct responses out of 44 words. $G f$ fluid intelligence (Raven's Progressive Matrices, see text), Gf scores represent total correct responses out of 48 at pretest. Range $=$ minimummaximum value

Significant differences between younger and older adults: $* * *$ $p<0.001$. * $p<0.05$.

\begin{tabular}{|c|c|c|c|c|c|c|}
\hline \multirow[t]{2}{*}{ Variable } & \multicolumn{3}{|c|}{ Younger adults } & \multicolumn{3}{|c|}{ Older adults } \\
\hline & $\begin{array}{l}\text { WM } \\
(n=22)\end{array}$ & $\begin{array}{l}\text { Implicit } \\
(n=20)\end{array}$ & $\begin{array}{l}\text { No-contact } \\
(n=21)\end{array}$ & $\begin{array}{l}\text { WM } \\
(n=22)\end{array}$ & $\begin{array}{l}\text { Implicit } \\
(n=20)\end{array}$ & $\begin{array}{l}\text { No-contact } \\
(n=23)\end{array}$ \\
\hline $\begin{array}{c}\text { Gender \% } \\
\text { women }\end{array}$ & 73 & 70 & 71 & 82 & 70 & 70 \\
\hline \multicolumn{7}{|c|}{ Age in years*** } \\
\hline$M$ & 24.68 & 24.35 & 25.52 & 67.64 & 67.7 & 68.61 \\
\hline$S D$ & 5.26 & 5.18 & 4.54 & 4.73 & 4.96 & 6.54 \\
\hline Range & $18-38$ & $19-38$ & $18-35$ & $61-81$ & $61-78$ & $60-84$ \\
\hline \multicolumn{7}{|l|}{ Health* } \\
\hline$M$ & 2.04 & 2.04 & 2.00 & 2.25 & 2.07 & 2.24 \\
\hline$S D$ & 0.45 & 0.43 & 0.26 & 0.31 & 0.50 & 0.38 \\
\hline Range & $1.29-2.86$ & $1.14-2.86$ & $1.57-2.57$ & $1.86-2.86$ & $1.29-3.00$ & $1.57-2.86$ \\
\hline \multicolumn{7}{|c|}{ Education in years } \\
\hline$M$ & 14.86 & 14.65 & 15.57 & 15 & 15.2 & 13.52 \\
\hline$S D$ & 2.03 & 1.81 & 2.38 & 2.51 & 2.76 & 1.71 \\
\hline Range & $12-19$ & $10-19$ & $12-21$ & $12-22$ & $11-22$ & $11-18$ \\
\hline \multicolumn{7}{|l|}{$\mathrm{Gc}^{* * *}$} \\
\hline$M$ & 34.59 & 35.15 & 33.76 & 39.32 & 38.00 & 38.30 \\
\hline$S D$ & 5.26 & 5.1 & 4.37 & 2.63 & 4.40 & 3.30 \\
\hline Range & $21-43$ & $17-42$ & $18-40$ & $34-43$ & $28-44$ & $32-43$ \\
\hline \multicolumn{7}{|l|}{ Gf*** } \\
\hline$M$ & 36.23 & 34.85 & 35.57 & 27.05 & 30.3 & 25.17 \\
\hline$S D$ & 5.82 & 6.12 & 5.48 & 7.55 & 6.87 & 6.10 \\
\hline Range & $24-45$ & $24-46$ & $22-43$ & $9-36$ & $14-42$ & $14-36$ \\
\hline
\end{tabular}

The purpose of the present work was to illustrate the proposed method by using cognitive plasticity data collected in younger and older adults (Bürki 2012). We analyzed data on training and transfer performance and compared a WM training group to an active and a passive training group. First, when analyzing training performance with standard analyses of variance, we expected to find training progress in both younger and older adults, but more pronounced in younger adults. Second, we explored individual differences in training performance by a LGCM analysis. Third, with regard to training effectiveness, we hypothesized larger training gains and transfer effects in pretest to posttest differences in younger adults compared to older adults. Finally, we examined the individual differences in the link between training performance, training gain and transfer effects.

\section{$\operatorname{Method}^{1}$}

\section{Participants}

A total of 128 individuals, 63 younger and 65 older adults met the inclusion criteria (i.e., aged between 18 and

${ }^{1}$ For a detailed description of the method see Bürki (2012).
38 years for the younger adults and 60 years and older for the older adults group, practice of French for at least 5 years) and participated in the study. The present study was approved by the ethics committee of the Faculty of Psychology and Educational Sciences of the University of Geneva. All participants signed a written informed consent for participation. Several control tests were performed such as the Freiburg Visual Acuity and Contrast Test (FrACT; Bach 1996) for visual acuity control, a self-rating health questionnaire and a crystallized intelligence test, the French adaptation of the Mill Hill Vocabulary Scale (Deltour 1993; Raven et al. 1998). The participants were pseudo-randomly (age-, gender- and education-matched) assigned to either a cognitive training group or an active or a passive control group. The experimental groups did not differ from each other within the age-groups regarding the characteristics listed in Table 1, to the exception of the total number of years of education $[F(2,62)=3.38$, $p=0.04]$. The older no-contact control group had significantly less years of education compared to its trained peers.

Procedure

All participants were individually tested in one session at pretest and one at posttest. A subsample additionally 


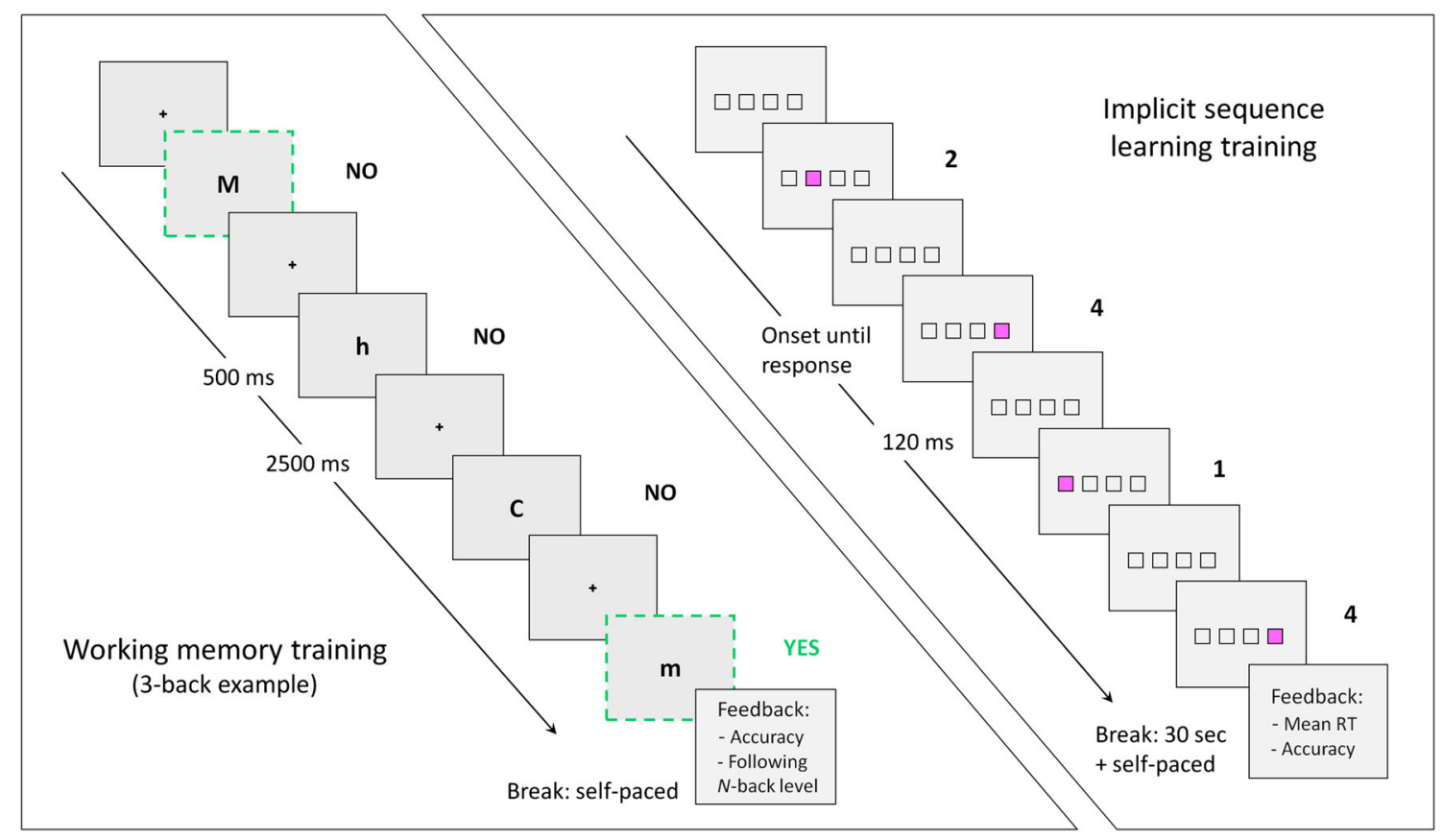

Fig. 1 Illustration of the training tasks. Left panel Working memory training illustrated with an example of a 3-back sequence in the adaptive $\mathrm{N}$-back task training. Right panel Implicit sequence learning training illustrated with a part of the trial sequence

participated in an EEG session described elsewhere (Bürki 2012). At pretest, participants completed a battery of cognitive tasks assessing WM, fluid intelligence, inhibition as well as perceptual-motor and processing speed. At posttest, after the training period, a similar session was administered. Between pretest and posttest, participants in the training groups performed ten training sessions distributed over 2-4 weeks. The participants were trained with either a WM task or an implicit sequence learning task. The training sessions lasted about 30 min per day and were administered individually. The control groups without training were not contacted during 2-4 weeks between pretest and posttest.

\section{Material}

\section{Working memory training}

The WM training group performed an adaptive verbal $N$-back task training adapted from the dual $\mathrm{N}$-back paradigm used by Jaeggi et al. (2008). A single task condition with verbal stimuli based on Chicherio (2006) and Ludwig et al. (2008) was used. The task consisted in judging whether the current letter matches the letter $N$ positions back in a sequence of letters presented one by one (see Fig. 1, left panel). The level of difficulty ( $N$-level) was varied by adapting the load in each block to the participant's performance reached in the preceding block.

\section{Implicit sequence learning training}

The active control group was trained with an implicit sequence learning task which served as a placebo training to control for the confounding variables resulting from a training setting. The goal was to present a task requiring as little attentional resources as possible during this training. Therefore, a simple implicit sequence learning task was chosen. The sequence should be implicitly learned while attentional control decreases and speed increases in the course of the training (Gaillard et al. 2009; Howard et al. 2004; Parkin 1993). The task consisted of four light gray squares presented horizontally aligned in the center of the screen (see Fig. 1, right panel). One stimulus consisted of one pink and three gray squares, each square changing color from gray to pink in turn. The participants had to respond as fast and as accurately as possible by pressing the key matching the position of the pink square. Similar to the WM training, 15 blocks per training session were provided.

\section{Pretest and posttest tasks}

As mentioned above, a battery of cognitive tests was administered before and after the training. It included first conditions of the trained task, a verbal 0-back and a verbal 2-back task in order to assess direct gains from training. Three near-transfer tasks were included: a spatial 0-back 
and 2-back task, structurally similar to the trained one (Braver et al. 1997; Chicherio 2006; Ludwig et al. 2008; Owen et al. 1999), and two WM tasks, a Number Updating task (Carretti et al. 2007) and a French adaptation of the Reading Span task (Daneman and Carpenter 1980; de Ribaupierre and Bailleux 1995; de Ribaupierre and Ludwig 2003; Delaloye et al. 2008). For the verbal and the spatial $\mathrm{N}$-back tasks, a WM load cost score was calculated, defined as the difference between 2-back and 0-back condition. Several far-transfer tasks were further included. First, a fluid intelligence measure, the Raven's Progressive Matrices (Raven 1958, 1962), was administered. In order to avoid a ceiling effect in younger adults and a floor effect in older adults, both versions, i.e., the Raven's Standard Progressive Matrices and the Raven's Advanced Progressive Matrices, were used. Odd and even trials of each version were separated and administered as different forms at pretest and posttest as described in Jaeggi et al. (2010). Second, an inhibition task, the computerized version of the Color Stroop task (Ludwig 2005; Ludwig et al. 2010; Spieler et al. 1996; Stroop 1935), was used. Finally, three processing speed tasks were included: The Letter and the Pattern Comparison tasks were developed by Salthouse and Babcock (1991) in order to assess the verbal and the visual information processing speed (de Ribaupierre 2001; de Ribaupierre et al. 2011), and the computerized simple reaction time (SRT) task measured the perceptual-motor speed (de Ribaupierre et al. 2011; Hultsch et al. 2000).

\section{Analyses}

First, we conducted standard analyses of variance on the training performance. The mean $N$-back level per training session for the WM training and the mean reaction times per training session for the implicit sequence learning training were used as dependent variables. A repeatedmeasures analysis of variance (ANOVA) was conducted including age-group (younger, older) as a between-subjects factor and training session (session 1-10) as a withinsubjects factor.

Second, we implemented LGCM analyses on the dependent variables of the training data (Duncan et al. 1999; Muthén 1991) to model the individual form of change over time and investigate systematic individual differences in growth as well as the antecedents and consequents of change (Preacher et al. 2008). Several model fit indexes were checked to select the best model. Given that the root-mean-square error of approximation tends to over reject models at small sample sizes (Hu and Bentler 1999), we retained $\chi^{2}$ test, standardized root-mean-square residual (SRMR), comparative fit index (CFI) and Tucker-Lewis index (TLI) for absolute model fit evaluation. Values of the SRMR smaller than .08 of the CFI above .90 and of the TLI above .95 were considered to reflect adequate model fit. Models were estimated with AMOS (Arbuckle 2009) using the maximum likelihood estimator. A model with a random intercept and a linear slope was fitted to the WM training data as well as to the implicit sequence learning training data (Duncan et al. 2006; Tisak and Meredith 1990). For the sake of parsimony, the variances of the 10 training sessions were fixed on the same estimated value. The linear slope model for the WM training data presented a good model fit $\left[\chi^{2}(59, n=44)=112.26, p<.000\right.$, SRMR $=$ $.04, \mathrm{CFI}=.92, \mathrm{TLI}=0.94]$ with the exception of the TLI value. We compared this model to a linear slope model with released error variances for the training sessions $\left[\chi^{2}(50, \quad n=44)=103.41, \quad p<.000, \quad\right.$ SRMR $=.03$, $\mathrm{CFI}=.92, \mathrm{TLI}=0.93]$. The fit did not change significantly $\left[\mathrm{d} \chi^{2}(9)=8.85\right]$, we therefore retained the first and more constrained model, that is, the model in which error variances were fixed.

We further assessed measurement invariance across the two age-groups. We tested whether the model fit differs significantly between a model where the error variances of the training sessions are assumed to be equal across groups versus a model where the error variances are left free to vary. The model fit difference was significant $\left[\mathrm{d} \chi^{2}(19)=54.54\right]$ between the equality constrained model $\left[\chi^{2}(119\right.$, $n=22)=212.22, p<.000, \quad$ SRMR $=.07, \quad$ CFI $=.82$, $\mathrm{TLI}=0.86)$ and the model without equality constraints $\left[\chi^{2}(100, \quad n=22)=157.68, \quad p<.000, \quad\right.$ SRMR $=.06$, $\mathrm{CFI}=.89, \mathrm{TLI}=0.90]$. The equality constraints do therefore not hold across the two age-groups, and error variances over time seem to differ between the two age-groups. Hence, the model has to be interpreted with care. However, the model fits were not good as indicated by CFI and TLI values, which is probably due to the small sample size.

In a next step, the effect of age-group on intercept and slope was examined by introducing it as a dummy variable predictor into the model. The effect of individual differences in fluid and crystallized intelligence, WM, inhibition and speed performance on intercept and slope was tested in separate models for each of these cognitive predictors while controlling for age-group. Significance was tested within each model separately. All cognitive predictors were measures from pretest assessment and were entered as grand mean-centered variables.

No adequate model fits were obtained for the implicit sequence learning training data, neither for a model with fixed error variances $\left[\chi^{2}(59, n=44)=780.05, p<0.000\right.$, $\mathrm{SRMR}=0.09, \mathrm{CFI}=0.45, \mathrm{TLI}=0.58]$ nor for a model with released error variances $\left[\chi^{2}(50, n=44)=459.94\right.$, $p<0.000, \mathrm{SRMR}=0.13, \mathrm{CFI}=0.68, \mathrm{TLI}=0.72]$.

Third, training gains and transfer effects were analyzed by comparing all experimental groups on the trained verbal $\mathrm{N}$-back task and on the transfer tasks. Training gains and 
transfer scores were calculated as the absolute difference between pretest and posttest performance. The scores of the respective dependent variable were submitted to a $2 \times 3$ two-way ANCOVA with age-group (young, older) and training group (WM training, implicit training, no-contact control) as between-subjects factors. Since the total number of years of education was significantly lower in the older no-contact control group compared with the older training groups, education was included as a covariable. Partial $\eta^{2}$ values were reported as effect size. Whenever variance homogeneity assumption was violated-checked with the Mauchly's test of sphericity-results with GreenhouseGeisser-adjusted degrees of freedom were reported. Significant interactions at an alpha level of $p<0.05$ were followed up by post hoc pairwise $t$ test comparisons with adjusted significance level using Bonferroni corrections to avoid family-wise alpha error inflation by multiple comparisons. The adjusted significance level was $p<0.001$ for the training performance, and $p<0.008$ for the training gains and transfer effects.

Finally, training gains and transfer scores were linked by correlational analyses with training improvements for the WM training group. The scores were correlated with the individual intercept and slope values derived from the LGCM. The correlations were examined in a conditional model controlling intercept and slope for the predictors age-group and fluid intelligence.

\section{Results}

Univariate analysis of training performance

Figure 2 shows the individual WM training curves as well as the age-group means. First, as mentioned above, analyses of variance were conducted on the scores obtained for

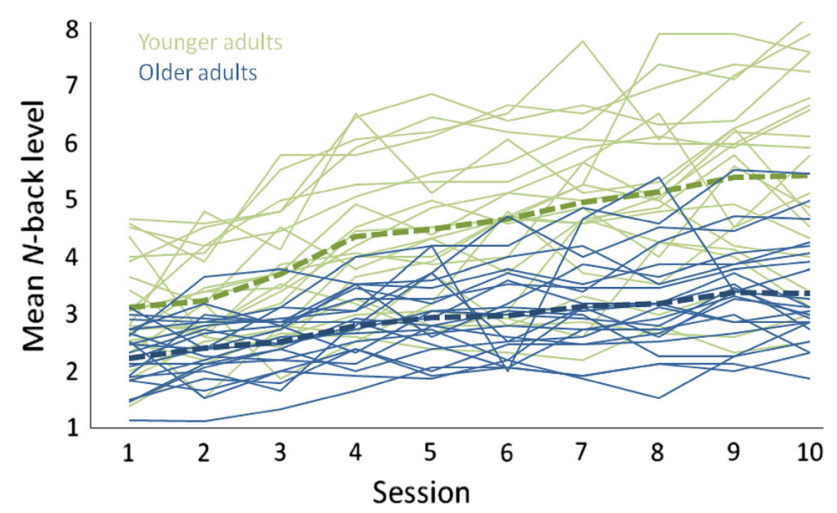

Fig. 2 Working memory training. Individual training curves of the averaged $N$-back level as a function of session; younger adults in light green (light gray), older adults in dark blue (dark gray), bold dashed lines represent the mean of each age-group (color figure online)

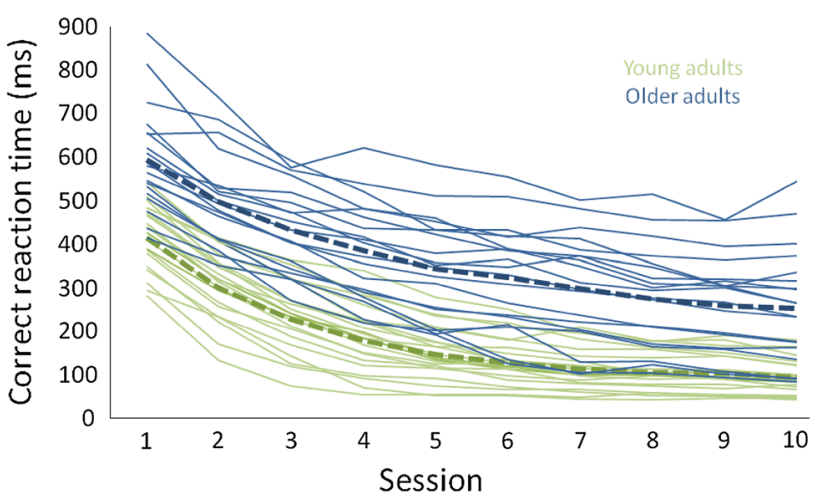

Fig. 3 Implicit sequence learning training. Individual training curves of the averaged correct reaction time as a function of session; younger adults in light green (light gray), older adults in dark blue (dark gray), bold dashed lines represent the mean of each age-group (color figure online)

each session. The Age x Session ANOVA revealed a significant effect of age $[F(1,42)=31.13, p<0.001$, $\left.\eta_{\mathrm{p}}^{2}=0.43\right] \quad$ and $\quad$ session $[F(4.41,185.24)=54.7$, $\left.p<0.001, \eta_{\mathrm{p}}^{2}=0.57\right]$ as well as a significant Age x Session interaction $[F(4.41,185.24)=6.62, p<0.001$, $\left.\eta_{\mathrm{p}}^{2}=0.14\right]$. Younger adults $(M=4.46, S D=0.2)$ exhibited a higher mean $N$-back level than older adults $(M=2.9, S D=0.2)$. For older adults, pairwise post hoc comparisons revealed that the first, second and third training sessions were significantly different from the fifth through the last session. No more significant improvements were observed from the fourth session on. For younger adults, however, performance improvements were significant up to the sixth training session. These results show that the older adults tended toward an asymptotic-like performance earlier than the younger adults. Age differences persisted throughout the 10 training sessions, but were larger toward the end of the training.

Training performance in the implicit sequence learning is presented in Fig. 3. The ANOVA revealed a significant effect of Age $\left[F(1,38)=46.06, p<0.001, \eta_{\mathrm{p}}^{2}=0.55\right]$ and Session $\left[F(2.05,77.78)=508.99, p<0.001, \eta_{\mathrm{p}}^{2}=0.93\right]$ and a significant Age $\mathrm{x}$ Session interaction $[F(2.05$, $\left.77.78)=3.73, p=0.024, \eta_{\mathrm{p}}^{2}=0.09\right]$. The post hoc comparisons revealed that all sessions were significantly different from each other with the exception of the ninth and tenth session for older adults and from the seventh to the tenth session for younger adults. Younger adults tended toward an asymptotic performance somewhat earlier than older adults who did so only in the last two training sessions. Age differences persisted throughout the ten training sessions.

Latent Analysis of Training Performance

Latent growth curve modeling using a linear model applied on the ten WM training sessions revealed a significant 
Fig. 4 Working memory training. Path diagram for the conditional linear growth curve model with age-group and Raven score (at pretest) as predictors. Observed variables in rectangles ( $S$ session), latent variables in circles ( $e$ error; Icept intercept). Regression paths are unstandardized coefficients; standardized coefficients are in parentheses

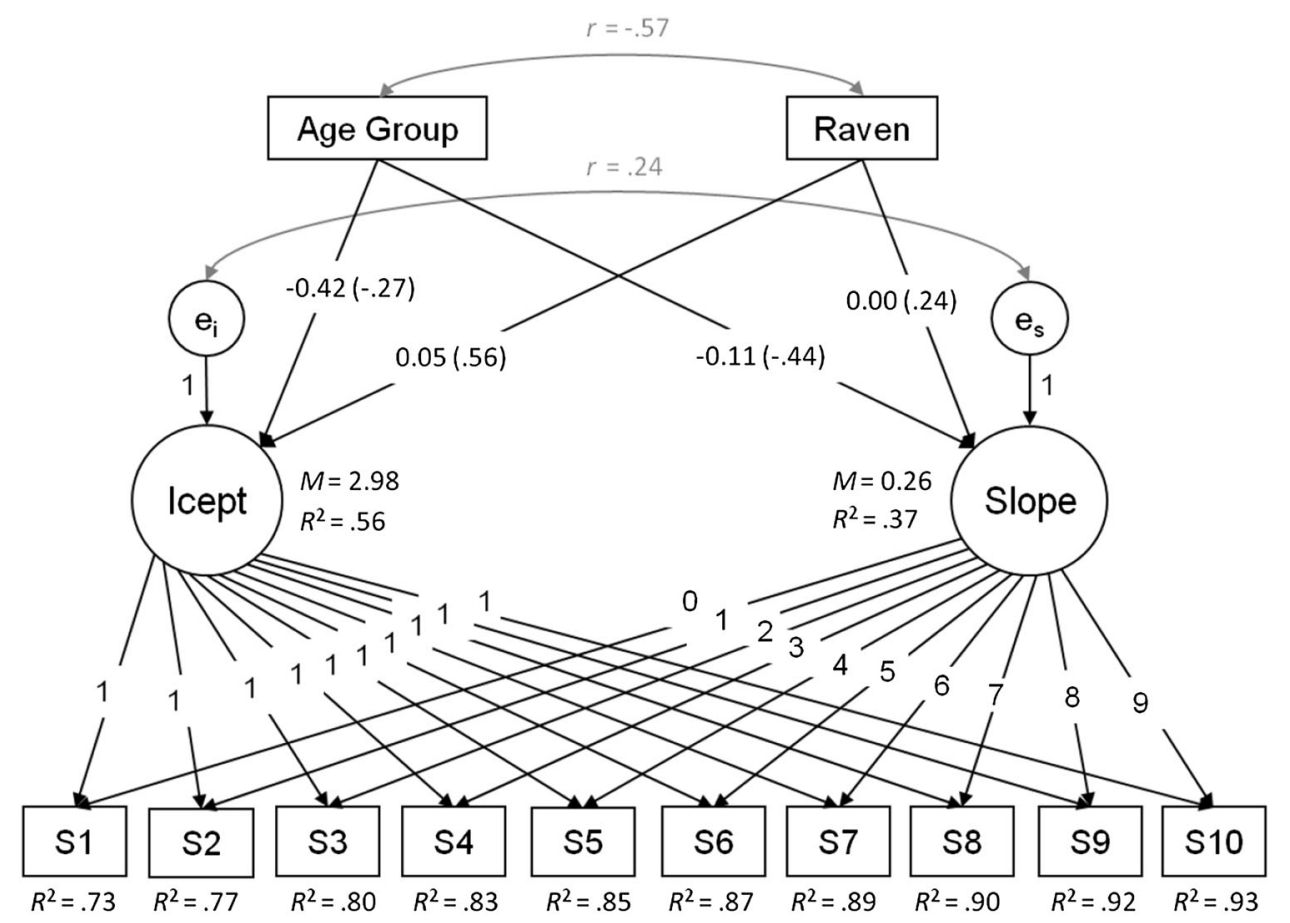

intercept of 2.77 ( $S E=0.13, p<0.001$ ) and a significant slope of $0.20\left(S E=0.02, p<0.001\right.$; model fit: $\chi^{2}(59$, $n=44)=112.26, \quad p<0.000, \quad$ SRMR $=0.04$, $\mathrm{CFI}=0.92$, TLI $=0.94)$. Slope and intercept were positively correlated $(r=0.56, \operatorname{cov}=0.05, p=0.003)$. This correlation suggested that individuals who started at a higher level of performance gained more in cognitive performance during the training.

The conditional model with age-group as predictor [model fit: $\chi^{2}(67, \quad n=44)=118.86, \quad p<0.000$, SRMR $=0.04, \mathrm{CFI}=0.93, \mathrm{TLI}=0.94]$ indicated that being in the one or the other age-group significantly predicted initial level and growth curve: For older adults, the initial level was 0.9 (std. coefficient $=-0.59, p<0.000$ ) $N$-back levels lower and slope was 0.14 (std. coefficient $=-0.58, p<0.000) N$-back levels lower than for younger adults. Age-group accounted for $35 \%$ of the total variance in intercept and for $33 \%$ of the total variance for slope. Slope and intercept were no longer correlated $(r=0.33, \mathrm{cov}=0.02, p=0.081)$.

To further examine the potential modifiers of training level and growth curve independently of age, LGCM analyses were repeated with each of the cognitive predictors separately, while controlling for age-group. Speed (std. coefficient $=-0.33, p=0.017$ ), fluid intelligence (std. coefficient $=0.56, p<0.000$ ), crystallized intelligence (std. coefficient $=0.3, p=0.047$ ) and the spatial $N$-back measures (std. coefficient $=0.42, p=0.001$ ) significantly predicted intercept when controlling for age. Reading span (std. $\quad$ coefficient $=0.42, \quad p<0.000 ; \quad$ slope: $\quad$ std. coefficient $=0.3, p=0.026)$ and the verbal $N$-back measures (intercept: std. coefficient $=0.54, p<0.000$; slope: std. coefficient $=0.29, p=0.035$ ) also significantly predicted slope. There was no significant effect of interference.

In all these models including cognitive variables next to age-group as predictors, age-group still significantly predicted slope and intercept with the exception when it was combined with fluid intelligence: Fluid intelligence performance was a significant predictor of intercept, whereas age-group now significantly predicted slope only [see Fig. 4; model fit: $\chi^{2}(75, n=44)=126.39, p<0.000$, SRMR $=0.04, \mathrm{CFI}=0.93$, TLI $=0.94]$. That is, with every additional point reached in the Raven score, the intercept increased by $0.05 \mathrm{~N}$-back levels (std. coefficient $=0.56, p<0.000$ ) while age-group predicted the difference between groups of $0.11 \mathrm{~N}$-back levels in the growth curve (std. coefficient $=-0.44, p=0.009$; lower score for older adults). These results suggest that high fluid intelligence ability predicted a high initial training performance while age-group predicted the development during training. Belonging to the younger group predicted a higher linear growth during training but did not predict the initial level. Together, the predictors age-group and fluid intelligence explained $56 \%$ of the variance in intercept and $37 \%$ in slope. The additional explained variance proper to fluid intelligence after controlling for age effects was $21 \%$ for intercept and $4 \%$ for slope. Slope and intercept were not significantly correlated in this model $(r=0.24$, $\operatorname{cov}=0.01, p=0.219)$. 
Table 2 Descriptive statistics for mean accuracy data of the $N$-back tasks presented as proportion; the proportion of correctly recalled numbers in the Updating Task; the average number of words correctly recalled per item for the Reading Span task; the total of correct responses in the Raven Progressive Matrices; the interference ratio of the Stroop task; the average response time in seconds for the Letter Comparison task and the Patter Comparison task; average response time in ms for the Simple Reaction Time (SRT) task; mean values at pretest and posttest, standard deviation in parentheses

\begin{tabular}{|c|c|c|c|c|c|c|}
\hline \multirow[t]{2}{*}{ Task } & \multicolumn{3}{|l|}{ Younger adults } & \multicolumn{3}{|l|}{ Older adults } \\
\hline & WM & Implicit & No-contact & WM & Implicit & No-contact \\
\hline \multicolumn{7}{|c|}{ Verbal 0-back } \\
\hline Pretest & $0.96(0.04)$ & $0.97(0.02)$ & $0.98(0.02)$ & $0.98(0.02)$ & $0.97(0.03)$ & $0.97(0.03)$ \\
\hline Posttest & $0.98(0.05)$ & $0.97(0.03)$ & $0.98(0.02)$ & $0.99(0.01)$ & $0.98(0.02)$ & $0.97(0.03)$ \\
\hline \multicolumn{7}{|c|}{ Verbal 2-back } \\
\hline Pretest & $0.91(0.08)$ & $0.93(0.06)$ & $0.91(0.05)$ & $0.86(0.11)$ & $0.90(0.08)$ & $0.84(0.12)$ \\
\hline Posttest & $0.96(0.05)$ & $0.94(0.05)$ & $0.92(0.08)$ & $0.96(0.05)$ & $0.92(0.08)$ & $0.87(0.11)$ \\
\hline \multicolumn{7}{|c|}{ Spatial 0-back } \\
\hline Pretest & $0.94(0.06)$ & $0.97(0.02)$ & $0.97(0.02)$ & $0.95(0.05)$ & $0.96(0.04)$ & $0.94(0.04)$ \\
\hline Posttest & $0.97(0.03)$ & $0.96(0.03)$ & $0.97(0.02)$ & $0.97(0.04)$ & $0.97(0.02)$ & $0.96(0.05)$ \\
\hline \multicolumn{7}{|c|}{ Spatial 2-back } \\
\hline Pretest & $0.92(0.06)$ & $0.94(0.06)$ & $0.91(0.08)$ & $0.85(0.13)$ & $0.91(0.08)$ & $0.84(0.14)$ \\
\hline Posttest & $0.93(0.08)$ & $0.93(0.06)$ & $0.92(0.10)$ & $0.93(0.06)$ & $0.94(0.05)$ & $0.86(0.13)$ \\
\hline \multicolumn{7}{|l|}{ Updating } \\
\hline Pretest & $0.59(0.20)$ & $0.63(0.21)$ & $0.46(0.25)$ & $0.57(0.22)$ & $0.44(0.20)$ & $0.39(0.21)$ \\
\hline Posttest & $0.70(0.21)$ & $0.66(0.21)$ & $0.52(0.21)$ & $0.49(0.24)$ & $0.44(0.21)$ & $0.43(0.19)$ \\
\hline \multicolumn{7}{|c|}{ Reading span } \\
\hline Pretest & $2.74(0.52)$ & $2.84(0.38)$ & $2.63(0.46)$ & $2.76(0.35)$ & $2.82(0.47)$ & $2.71(0.45)$ \\
\hline Posttest & $2.91(0.41)$ & $2.97(0.41)$ & $2.87(0.30)$ & $2.88(0.34)$ & $2.88(0.48)$ & $2.82(0.32)$ \\
\hline \multicolumn{7}{|l|}{ Raven } \\
\hline Pretest & $36.23(5.82)$ & $34.85(6.12)$ & $35.57(5.48)$ & $27.05(7.55)$ & $30.30(6.87)$ & $25.17(6.10)$ \\
\hline Posttest & $37.41(6.43)$ & $35.95(7.35)$ & $36.86(6.55)$ & $28.86(7.10)$ & $31.20(6.67)$ & $27.61(6.82)$ \\
\hline \multicolumn{7}{|l|}{ Stroop } \\
\hline Pretest & $0.29(0.11)$ & $0.25(0.12)$ & $0.31(0.16)$ & $0.34(0.12)$ & $0.32(0.13)$ & $0.34(0.14)$ \\
\hline Posttest & $0.22(0.13)$ & $0.20(0.11)$ & $0.30(0.23)$ & $0.29(0.10)$ & $0.29(0.15)$ & $0.33(0.13)$ \\
\hline \multicolumn{7}{|c|}{ Letter Comparison } \\
\hline Pretest & $65.59(17.86)$ & $59.23(16.12)$ & $58.49(17.27)$ & $81.51(15.75)$ & $83.73(20.29)$ & 77.70 (18.09) \\
\hline Posttest & $63.79(21.83)$ & $60.22(20.20)$ & $60.00(16.94)$ & $80.70(15.44)$ & $78.16(17.76)$ & $75.65(11.81)$ \\
\hline \multicolumn{7}{|c|}{ Pattern Comparison } \\
\hline Pretest & $52.00(13.14)$ & 51.67 (11.29) & $49.25(14.05)$ & $75.00(18.79)$ & $70.70(18.85)$ & $73.28(19.31)$ \\
\hline Posttest & $51.33(16.34)$ & $49.92(11.55)$ & $48.41(15.48)$ & $73.78(10.76)$ & $67.82(11.63)$ & 71.35 (16.19) \\
\hline \multicolumn{7}{|l|}{ SRT } \\
\hline Pretest & 304 (53) & 278 (44) & 289 (39) & $342(41)$ & 328 (49) & 309 (49) \\
\hline Posttest & $295(48)$ & $274(32)$ & $292(56)$ & $353(55)$ & 317 (54) & $321(73)$ \\
\hline
\end{tabular}

Training effectiveness

Descriptive data of the raw pretest and posttest scores are provided in Table 2. The ANOVA on the training gain score of the proportion of correct responses in the trained verbal 2-back task yielded a significant effect of Age $[F(1$, $\left.121)=5.64, p=0.019, \eta_{\mathrm{p}}^{2}=0.05\right]$ and Training $[F(2$, $\left.121)=10.66, p<0.001, \eta_{\mathrm{p}}^{2}=0.15\right]$, but no significant Age $\mathrm{x}$ Training interaction $[F(2,121)=1.13, p=0.273$, $\left.\eta_{\mathrm{p}}^{2}=0.02\right]$. Pairwise comparisons revealed that younger adults $(M=0.03, S D=0.06)$ had a significantly lower gain score than older adults $(M=0.06, S D=0.08)$. The average gain score was significantly higher for the WM training group $(M=0.08, S D=0.09)$ than for the implicit training group $(M=0.02, S D=0.05)$ and the no-contact control group $(M=0.02, S D=0.06)$. The latter two did not differ significantly. The analysis on the transfer score of the proportion of correct responses in the untrained spatial 2-back task yielded a significant effect of age $[F(1,121)=8.78, p=0.004$, $\left.\eta_{\mathrm{p}}^{2}=0.07\right]$ and training $[F(2,121)=3.28, p=0.041$, 
Table 3 Correlations between WM training intercept and slope with training gain and transfer scores for the conditional model with agegroup and the Raven score as predictors

\begin{tabular}{lll}
\hline Variable & Intercept & Slope \\
\hline Gain scores & & \\
Verbal 2-back & -0.15 & -0.07 \\
Verbal WM load cost & -0.18 & -0.21 \\
Transfer scores & & \\
Spatial 2-back & -0.21 & -0.20 \\
Spatial WM load cost & -0.12 & $-0.28+$ \\
Updating & -0.07 & $-0.40^{*}$ \\
Reading span & -0.13 & -0.11 \\
Raven & -0.21 & $-0.30+$ \\
Stroop interference ratio & -0.25 & -0.07 \\
Letter Comparison RT & $-0.39 *$ & -0.06 \\
Pattern Comparison RT & -0.03 & -0.12 \\
SRT task & -0.04 & $-0.32+$ \\
\hline$R T$ r & &
\end{tabular}

$R T$ response time, $S R T$ simple reaction time, WM load cost $=$ difference 2-back-0-back.

$* p<0.05 .+p<0.10 . n=44$

$\left.\eta_{\mathrm{p}}^{2}=0.05\right]$, but no significant Age $\times$ Training interaction $\left[F(2,121)=1.42, p=0.247, \eta_{\mathrm{p}}^{2}=0.02\right]$. Younger adults $(M=0.004, S D=0.06)$ had significantly lower transfer scores than older adults $(M=0.05, S D=0.09)$. Pairwise comparisons revealed that the WM training group had a marginally significantly higher average transfer score $(M=0.05, S E=0.09)$ than the implicit training group $(M=0.01, S E=0.04)$ and the no-contact control group $(M=0.01, S E=0.09)$. The latter two groups did not differ significantly. For the remaining pretest and posttest tasks, analyses did not reveal any significant transfer effect.

\section{Linking training performance and training effectiveness}

Training gains and transfer scores were linked with training performance for the WM training group in the latent analyses of training performance. The training gain (difference score between pretest and posttest performance of the verbal 2-back task) and all transfer scores were correlated with intercept and slope values of the training performance while controlling intercept and slope for agegroup and fluid intelligence (see Table 3).

The results revealed that the correlation between spatial WM load cost (difference between 2-back and 0-back condition) and slope reached marginal significance. This means that the gradient of the growth curve was positively associated with transfer score beyond the effect of age and fluid intelligence. Those who improved more during training showed more gain in a near-transfer task. In terms of the remaining transfer tasks, the Updating task, the Raven task, the Letter Comparison task and the SRT task, transfer scores showed a significant positive correlation with intercept or slope. The correlation with intercept revealed that the Letter Comparison transfer score was high for participants who showed a high initial training level. The correlation with slope indicated that the participants who showed a steep training curve also showed a high transfer score in the Updating, the Raven and the SRT task, beyond the effect of age and fluid intelligence.

\section{Discussion}

The aim of the present article was to propose a specific type of data analysis of individual differences in cognitive plasticity, namely LGCM, allowing estimating individual differences in initial training performance and performance changes, investigating their predictive power as well as their correlations with training gains and transfer scores. An illustration of the analysis was presented using data of a 10-day WM training in younger and older adults.

With regard to the standard analyses of variance of the WM training, we found preserved cognitive plasticity in older adults, but less pronounced than in younger adults; this is in line with the literature (e.g., Baltes and Kliegl 1992; Brehmer et al. 2012; Shing et al. 2008). Both agegroups reached a limit in performance over the course of training and the learning curve seemed to become asymptotic; one can therefore consider that the participants were pushed to their limits (Kliegl et al. 1989). Older adults reached the performance limit earlier than younger adults, which resulted in a magnification of age differences by the end of the WM training and is in line with the results from other training research (Brehmer et al. 2012; Kliegl et al. 1990).

As concerns the implicit memory training, response times decreased in both age-groups over the course of training. Younger adults reached their limit earlier than older adults. Response times were generally longer in older adults, but the amount of learning was similar between groups. This confirms the findings that the implicit learning rate is attenuated with age but that the total amount of plasticity in implicit learning is preserved (Daselaar et al. 2003; Parkin 1993).

Individual growth curve analysis of the WM training performance showed that the shape of growth is well described by a linear slope model, even though performance reaches a limit by the last sessions. The LGCM revealed that younger adults started training at a higher level (intercept) and improved faster during training (steeper linear slope). This pattern results in a magnification of age differences by the end of the training. With agegroup and fluid intelligence as predictors, analyses revealed that the latter was a significant predictor of the initial 
training performance, but not of the training improvement. Age-group, by contrast, was a significant predictor of the training improvement, but not of the initial training performance. Individual differences in fluid intelligence performance seem to explain individual differences in initial training performance, independent of age-group. Agegroup in turn predicts individual differences in training progression, that is, in cognitive plasticity, beyond individual differences in fluid intelligence. Results are in line with previous cognitive plasticity research, where age has been reported to explain unique variance at the end of the training (Kliegl et al. 1990). However, by introducing latent analysis, we were able to refine the analysis of the initial training performance. Individual differences in cognitive performance (Raven's Progressive Matrices) did predict the initial training level, but age predicted the amount of cognitive plasticity. Intercept and slope were no longer correlated after controlling for both cognition and age. Hence, taking into account age and individual differences in cognitive performance uncovered the independence of the amount of individual cognitive plasticity from the individual initial performance level.

One can now ask which mechanisms underlie the variable age. Indeed, the variable age may reflect a confound of influences, notably biological and sociocultural factors. In older adulthood, age probably reflects the increasing influence of biological factors and the decreasing efficacy of cultural factors with advancing age (Baltes 1997; de Ribaupierre et al. 2005, 2003). The initial level of training was predicted by differences in fluid intelligence, independent of age; however, once the limits of performance reached, the negative influence of age becomes apparent beyond individual differences in fluid intelligence. This effect of age on cognitive plasticity might be related to a general neurobiological mechanism. That mechanism represents a common factor influencing the integrity of the cognitive processes across a wide range of brain regions with advancing age such that the performance in many different tasks is affected and so maybe also cognitive plasticity (Baltes and Lindenberger 1997; Li and Lindenberger 2002).

Training effectiveness was equivalent, as concerns the verbal 2-back task, in younger and older WM training groups. The result is to a certain extent in line with the training literature, for example with the study of $\mathrm{Li}$ et al. (2008), where younger and older adults also exhibited similar training gain.

The near-transfer effect in the structurally similar spatial $\mathrm{N}$-back task also replicated findings from previous studies (e.g., Brehmer et al. 2012; Buschkuehl et al. 2008; Karbach and Kray 2009; Li et al. 2008; Richmond et al. 2011; Schmiedek et al. 2010). The fact that younger and older adults exhibited similar transfer effects is in line with some training studies (Karbach and Kray 2009; Li et al. 2008) but contradicts others (Dahlin et al. 2008) which reported transfer effects in younger adults but not in older adults. No additional transfer effects, that is, transfer to other tasks, were observed. This result is in line with recent WM training studies ( $\mathrm{Li}$ et al. 2008; Zinke et al. 2012) in which far-transfer effects were not reported, either in younger or in older adults. Still, our findings are partially in contrast to several recent WM training studies where far-transfer effects in younger adults and in some studies also in older adults were found (Borella et al. 2010; Brehmer et al. 2012; Buschkuehl et al. 2008; Dahlin et al. 2008; Mahncke et al. 2006; Richmond et al. 2011; Schmiedek et al. 2010).

We demonstrated the importance of including control groups in training studies. Test-retest effects and the placebo training effect (implicit training) were present; however, the latter did most often not exceed test-retest effects. This confirms that, as hypothesized, the implicit training did not tax updating processes. Effects of placebo were therefore very small.

A shortcoming of the present study is the potential ceiling effect in the verbal and spatial $N$-back tasks at pretest and posttest in younger adults. This is a very common problem in developmental and aging research, since the challenge is to find a task which assesses the performance level of both younger and older adults. The ceiling effect may have biased age differences in training gain preventing demonstrating any transfer effects. Younger adults might have shown more training effects if there had been more room for performance improvement from pretest to posttest. In order to further examine this possible bias, accuracy data were reanalyzed in different exploratory ways. First, we reanalyzed data after excluding potential ceiling participants from the sample. We identified and excluded the top third in accuracy performance at pretest, for each experimental group separately. Second, we checked for robustness of the ANOVA by a Tobit model which takes into account the censored nature of data (for details, see Bürki 2012). The results of these additional analyses did not show a change in results and confirmed the above reported findings. However, even by implementing these analyses, we were not able to completely exclude the possibility that there may exist ceiling effects in the $N$-back tasks.

We further investigated the link between individual intercept and slope values of the WM training, on the one hand, and gain scores as well as transfer scores, on the other hand, while controlling for the effect of age-group and individual differences in fluid intelligence level. This allowed us to examine the individual differences in cognitive plasticity independent of age effects and of individual differences in cognitive performance. No association between training gain scores (verbal $\mathrm{N}$-back task at pretest 
and posttest) and initial training performance as well as training slope was found. This may be due to the lack of variance as a result of the ceiling effect in the verbal $N$-back task as discussed above. In terms of transfer scores, there were positive associations between slope and transfer scores in spatial $N$-back task, Updating task, Raven and SRT task. The association was positive, that is, individuals showing more cognitive plasticity also showed larger transfer scores. By the individual analysis of cognitive plasticity and controlling for age and fluid intelligence, we were able to detect a link between growth curve and transfer effects.

By implementing a LGCM approach, we were able to increase the explained variance in cognitive plasticity. We were further able to show that the initial training performance and cognitive plasticity are independent and mediated differently by age and by individual differences in cognitive performance. This result indicates that the individual analysis of plasticity should begin at the training performance, and not only focus on the difference in performance between pretest and posttest. With the sole analysis of pretest and posttest performances, important information is neglected.

LGCM analysis is not without limits, in particular with regard to its application in training research. It requires a large sample size which is frequently difficult to obtain in training studies. The sample size in the present study was rather small for an application of LGCM analysis, in particular for the assessment of the measurement invariance across groups. However, the model fit indexes for the WM training were acceptable so that the analysis was tenable. Furthermore, we were not able to model a growth shape other than a linear slope function. It may be meaningful to model in addition an asymptotic growth shape for instance, since the univariate analysis of training performance revealed an asymptotic-like performance limit.

In sum, a substantial part of the variance in training performance remained unexplained, suggesting that other variables may account for individual differences in cognitive plasticity. We propose to include further predictors into a LGCM analysis such as social aspects, metacognitive self-regulation or motivation which were recently proposed as powerful tools to foster successful training (Borella et al. 2010; Hertzog and Dunlosky 2012; McDaniel and Bugg 2012; Redick et al. 2013). The inclusion of a broader range of possible predictors will provide further insights into individual differences in cognitive plasticity and allow designing individually adjusted training programs.

As recently stated, there is currently little evidence that memory interventions (...) are relevant to the ultimate goal of training, which is to support older adults to remain independent longer by reducing, remediating, or reversing functional impairments (Zelinski 2012). We believe that research which focuses on the analysis of individual differences in cognitive plasticity represents a significant cornerstone on the way to reach this ultimate goal of training.

Acknowledgments This study was supported by the Hedwig Widmer Foundation, Zurich, Switzerland. The authors thank Philippe Golay and Paolo Ghisletta for the support regarding the application and the selection of the latent growth curve model. This study is based on Céline Bürki's doctoral dissertation (Bürki 2012).

\section{References}

Arbuckle, J. L. (2009). Amos (Version 18.0) [Computer Program]. Chicago: SPSS.

Bach, M. (1996). The "Freiburg visual acuity test": Automatic measurement of visual acuity. Optometry and Vision Science, 73, 49-53.

Ball, K., Edwards, J. D., \& Ross, L. A. (2007). Cognitive interventions and aging: The impact of speed of processing training on cognitive and everyday functions. Journals of Gerontology: Psychological Sciences, 62B, 19-31.

Baltes, P. B. (1997). On the incomplete architecture of human ontogeny: Selection, optimization, and compensation as foundation of developmental theory. American Psychologist, 52, 366-380.

Baltes, P. B., \& Baltes, M. M. (1990). Successful aging: Perspectives from the behavioral sciences. Cambridge, UK: Cambridge University Press.

Baltes, P. B., \& Kliegl, R. (1992). Further testing of limits of cognitive plasticity: Negative age differences in a mnemonic skill are robust. Developmental Psychology, 28, 121-125.

Baltes, P. B., Kliegl, R., \& Dittmann-Kohli, F. (1988). On the locus of training gains in research on the plasticity of fluid intelligence in old age. Journal of Educational Psychology, 80, 392-400.

Baltes, P. B., \& Lindenberger, U. (1988). On the range of cognitive plasticity in old age as a function of experience: 15 years of intervention research. Behavior Therapy, 19, 283-300.

Baltes, P. B., \& Lindenberger, U. (1997). Emergence of a powerful connection between sensory and cognitive functions across the adult life span: A new window to the study of cognitive aging? Psychology and Aging, 12, 12-21.

Bissig, D., \& Lustig, C. (2007). Training memory: Who benefits from memory training? Psychological Science, 8, 720-726.

Borella, E., Carretti, B., Riboldi, F., \& Beni, R. D. (2010). Working memory training in older adults: Evidence of transfer and maintenance effects. Psychology and Aging, 25, 767-778.

Braver, T. S., Cohen, J. D., Nystrom, L. E., Jonides, J., Smith, E. E., \& Noll, D. C. (1997). A parametric study of prefrontal cortex involvement in human working memory. Neuroimage, 5, 49-62.

Brehmer, Y., Westerberg, H., \& Bäckman, L. (2012). Working-memory training in younger and older adults: Training gains, transfer, and maintenance. Frontiers in human neuroscience, 6, 1-7.

Bürki, C. N. (2012). Cognitive training in younger and older adults: Effects on brain and behavior. Doctoral Thesis, University of Geneva, Geneva, Switzerland. http://archive-ouverte.unige.ch/ unige: 26490 .

Buschkuehl, M., Jaeggi, S. M., Hutchison, S., Perrig-Chiello, P., Däpp, C., Müller, M., et al. (2008). Impact of working memory training on memory performance in old-old adults. Psychology and Aging, 23, 743-753.

Carretti, B., Borella, E., \& Beni, R. D. (2007). Does strategic memory training improve the working memory performance of younger and older adults? Experimental Psychology, 54, 311-320. 
Chicherio, C. (2006). Contrôle exécutif et réseaux neurofonctionnels au cours du vieillissement normal: Un test de l'hypothèse de dédifférenciation cognitive. Unpuplished Doctoral Thesis, Université de Genève, Genève, Suisse.

Dahlin, E., Nyberg, L., Bäckman, L., \& Neely, A. S. (2008). Plasticity of executive functioning in young and older adults: Immediate training gains, transfer, and long-term maintenance. Psychology and Aging, 23, 720-730.

Daneman, M., \& Carpenter, P. A. (1980). Individual differences in working memory and reading. Journal of Verbal Learning and Verbal Behavior, 19, 450-466.

Daselaar, S. M., Rombouts, S. A. R. B., Veltman, D. J., Raaijmakers, J. G. W., \& Jonker, C. (2003). Similar network activated by young and old adults during the acquisition of a motor sequence. Neurobiology of Aging, 24, 1013-1019.

de Ribaupierre, A. (2001). Working memory and attentional processes across the lifespan. In P. Graf \& N. Otha (Eds.), Lifespan development of human memory (pp. 59-80). Cambridge, MA: MIT Press.

de Ribaupierre, A., \& Bailleux, C. (1995). Development of attentional capacity in childhood: A longitudinal study. In F. E. Weinert \& W. Schneider (Eds.), Memory performance and competencies: Issues in growth and development (pp. 45-70). Mahwah: Lauwrence Erlbaum.

de Ribaupierre, A., Fagot, D., \& Dirk, J. (2009). Déclin et plasticité des fonctions cognitives avec l'âge: Une question de différences individuelles? In M. Oris, E. Widmer, A. de Ribaupierre, D. Joye, D. Spini, G. Labouvie-Vief, et al. (Eds.), Transitions dans le parcours de vie et construction des inégalités (pp. 313-333). Lausanne, Switzerland: Presses Polytechniques et Universitaires Romandes.

de Ribaupierre, A., Fagot, D., \& Lecerf, T. (2011). Working memory capacity and its role in cognitive development. In P. Barrouillet \& V. Gaillard (Eds.), Cognitive development and working memory (pp. 105-133). East Sussex: Psychology Press.

de Ribaupierre, A., \& Ludwig, C. (2003). Age differences and divided attention: Is there a general deficit? Experimental Aging Research, 29, 79-105.

de Ribaupierre, A., Poget, L., \& Pons, F. (2005). The age variable in cognitive developmental psychology. In C. Sauvain-Dugerdil, H. Leridon, \& N. Mascie-Taylor (Eds.), Human clocks. The biocultural meanings of age (pp. 101-123). Bern, Switzerland: Peter Lang.

de Ribaupierre, A., Pons, F., and Poget, L. (2003). L'âge en psychologie du développement cognitif : Une variable explicative ? In J.-P. F. S. Cavalli (Ed.), L'avenir : Attentes, projets (dés)illusions, ouvertures. Hommages à Christian Lalive d'Epinay Lausanne: Réalités sociales.

Delaloye, C., Ludwig, C., Borella, E., Chicherio, C., \& de Ribaupierre, A. (2008). L'Empan de lecture comme épreuve mesurant la capacité de mémoire de travail: normes basées sur une population francophone de 775 adultes jeunes et âgés. Revue européenne de psychologie appliquée, 58, 89-103.

Deltour, J. J. (1993). Echelle de Vocabulaire Mill Hill de J. C. Raven. Braine de Chateau, Belgium: Editions L'Application des Techniques Modern S.P.R.L.

Duncan, T. E., \& Duncan, S. C. (2009). The ABC's of LGM: An introductory guide to latent variable growth curve modeling. Social and Personality Psychology Compass, 3, 979-991.

Duncan, T. E., Duncan, S. C., \& Strycker, L. A. (2006). An introduction to latent variable growth curve modeling: Concepts, issues, and application (2nd ed.). Mahwah, NJ: Lawrence Erlbaum.

Duncan, T. E., Duncan, S. C., Strycker, L. A., Li, F., \& Alpert, A. (1999). An introduction to latent variable growth curve modeling: Concepts, issues and applications. Mahwah, NJ: Lawrence Erlbaum Associates.

Edwards, J. D., Wadley, V. G., Myers, R. S., Roenker, D. L., Cissell, G. M., \& Ball, K. K. (2002). Transfer of a speed of processing: Intervention to near and far cognitive functions. Gerontology, 48, 329-340.

Engle, R. W., Kane, M. J., \& Tuholski, S. W. (1999). Individual differences in working memory capacity and what they tell us about controlled attention, general fluid intelligence, and functions of the prefrontal cortex. In A. Miyake \& P. Shah (Eds.), Models of working memory. Mechanisms of active maintenance and executive control (pp. 102-134). Cambridge, UK: Cambridge University Press.

Gaillard, V., Destrebecqz, A., Michiels, S., \& Cleeremans, A. (2009). Effects of age and practice in sequence learning: A graded account of ageing, learning, and control. European Journal of Cognitive Psychology, 21, 255-282.

Gross, A. L., Rebok, G. W., Unverzagt, F. W., Willis, S. L., \& Brandt, J. (2011). Cognitive predictors of everyday functioning in older adults: Results from the ACTIVE cognitive intervention trial. The Journals of Gerontology Series B: Psychological Sciences and Social Sciences, 66B, 557-566.

Hager, W., \& Hasselhorn, M. (1998). The effectiveness of the cognitive training for children from a differential perspective: A metaevaluation. Learning and Instruction, 8, 411-438.

Hertzog, C., \& Dunlosky, J. (2012). Metacognitive approaches can promote transfer of training: Comment on McDaniel and Bugg. Journal of Applied Research in Memory and Cognition, 1, 61-63.

Hertzog, C., Kramer, A. F., Wilson, R. S., \& Lindenberger, U. (2009). Enrichment effects on adult cognitive development: Can the functional capacity of older adults be preserved and enhanced? Psychological Science in the Public Interest, 9, 1-65.

Howard, D. V., Howard, J. H, Jr, Japikse, K., DiYanni, C., Thompson, A., \& Somberg, R. (2004). Implicit sequence learning: Effects of level of structure, adult age, and extended practice. Psychology and Aging, 19, 79-92.

Hu, L., \& Bentler, P. M. (1999). Cutoff criteria for fit indexes in covariance structure analysis: Conventional criteria versus new alternatives. Structural Equation Modeling: A Multidisciplinary Journal, 6, 1-55.

Hultsch, D. F., MacDonald, S. W. S., Hunter, M. A., Levy-Bencheton, J., \& Strauss, E. (2000). Intraindividual variability in cognitive performance in older adults: Comparison of adults with mild dementia, adults with arthritis, and healthy adults. Neuropsychology, 14, 588-598.

Jackson, J. J., Hill, P. L., Payne, B. R., Roberts, B. W., \& StineMorrow, E. A. L. (2012). Can an old dog learn (and want to experience) new tricks? Cognitive training increases openness to experience in older adults. Psychology and Aging, 27, 286.

Jaeggi, S. M., Buschkuehl, M., Jonides, J., \& Perrig, W. J. (2008). Improving fluid intelligence with training on working memory. Proceedings of the National Academy of Sciences of the United States of America, 105, 6829-6833.

Jaeggi, S. M., Studer-Luethi, B., Buschkuehl, M., Su, Y.-F., Jonides, J., \& Perrig, W. J. (2010). The relationship between n-back performance and matrix reasoning: Implications for training and transfer. Intelligence, 38, 625-635.

Jones, R. N., Rosenberg, A. L., Morris, J. N., Allaire, J. C., McCoy, K. J. M., Marsiske, M., et al. (2005). A growth curve model of learning acquisition among cognitively normal older adults. Experimental Aging Research, 31, 291-312.

Karbach, J., \& Kray, J. (2009). How useful is executive control training? Age differences in near and far transfer of taskswitching training. Developmental Science, 12, 978-990. 
Kliegel, M., \& Bürki, C. (2012). Memory training interventions require a tailor-made approach. Journal of Applied Research in Memory and Cognition, 1, 58-60.

Kliegl, R., Smith, J., \& Baltes, P. B. (1989). Testing-the-limits and the study of adult age differences in cognitive plasticity of a mnemonic skill. Developmental Psychology, 25, 247-256.

Kliegl, R., Smith, J., \& Baltes, P. B. (1990). On the locus and process of magnification of age differences during mnemonic training. Developmental Psychology, 26, 894-904.

Klingberg, T. (2010). Training and plasticity of working memory. Trends in Cognitive Sciences, 14, 317-324.

Klingberg, T., Fernell, E., Olesen, P. J., Johnson, M., Gustafsson, P., Dahlström, K., et al. (2005). Computerized training of working memory in children with ADHD: A randomized, controlled trial. Journal of the American Academy of Child and Adolescent Psychiatry, 44, 177-186.

Klingberg, T., Forssberg, H., \& Westerberg, H. (2002). Training of working memory in children with ADHD. Journal of Clinical and Experimental Neuropsychology, 24, 781-791.

Li, K. Z. H., \& Lindenberger, U. (2002). Relations between aging sensory/sensorimotor and cognitive functions. Neuroscience and Biobehavioral Reviews, 26, 777-783.

Li, S.-C., Schmiedek, F., Huxhold, O., Röcke, C., Smith, J., \& Lindenberger, U. (2008). Working memory plasticity in old age: Practice gain, transfer, and maintenance. Psychology and Aging, 23, 731-742.

Lövdén, M., Brehmer, Y., Li, S.-C., and Lindenberger, U. (2012). Training-induced compensation versus magnification of individual differences in memory performance. Frontiers in human neuroscience, 6 .

Lövdén, M., Ghisletta, P., \& Lindenberger, U. (2004). Cognition in the Berlin aging study (BASE): The first 10 years. Aging, Neuropsychology, and Cognition, 11, 104-133.

Ludwig, C. (2005). Age and individual differences in attentional control: A behavioral study. Unpuplished Doctoral Thesis, Université de Genève, Genève, Suisse.

Ludwig, C., Borella, E., Tettamanti, M., \& de Ribaupierre, A. (2010). Adult age differences in the Color Stroop Test: A comparison between an Item-by-item and a Blocked version. Archives of Gerontology and Geriatrics, 51, 135-142.

Ludwig, C., Chicherio, C., Terraneo, L., Magistretti, P., Ribaupierre, A. D., \& Slosman, D. (2008). Functional imaging studies of cognition using 99mTc-HMPAO SPECT: Empirical validation using the n-back working memory paradigm. European Journal of Nuclear Medicine and Molecular Imaging, 35, 695-703.

Mahncke, H. W., Connor, B. B., Appelman, J., Ahsanuddin, O. N., Hardy, J. L., Wood, R. A., et al. (2006). Memory enhancement in healthy older adults using a brain plasticity-based training program: A randomized, controlled study. Proceedings of the National Academy of Sciences, 103, 12523-12528.

McDaniel, M. A., \& Bugg, J. M. (2012). Memory training interventions: What has been forgotten? Journal of Applied Research in Memory and Cognition, 1, 45-50.

Muthén, B. (1991). Analysis of longitudinal data using latent variable models with varying parameters. In L. M. C. J. L. Horn (Ed.), Best methods for the analysis of change: Recent advances, unanswered questions, future directions (Vol. 1, pp. 1-17). Washington, DC: American Psychological Association.

Olesen, P. J., Westerberg, H., \& Klingberg, T. (2004). Increased prefrontal and parietal activity after training of working memory. Nature Neuroscience, 7, 75-79.

Owen, A. M., Herrod, N. J., Menon, D. K., Clark, J. C., Downey, S. P. M. J., Carpenter, T. A., et al. (1999). Redefining the functional organization of working memory processes within human lateral prefrontal cortex. European Journal of Neuroscience, 11, $567-574$.
Parkin, A. J. (1993). Implicit memory across the lifespan. In P. Graf \& M. E. J. Masson (Eds.), Implicit memory: New directions in cognition, development, and neuropsychology (pp. 191-206). Hillsdale, NJ, England: Lawrence Erlbaum Associates.

Perrig, W. J., Hollenstein, M., \& Oelhafen, S. (2009). Can we improve fluid intelligence with training on working memory in persons with intellectual disabilities? Journal of Cognitive Education and Psychology, 8, 148-164.

Preacher, K. J., Wichman, A. L., MacCallum, R. C., and Briggs, N. E. (2008). Latent growth curve modeling: Sage Publications, Inc.

Ram, N., Rabbitt, P., Stollery, B., \& Nesselroade, J. R. (2005). Cognitive performance inconsistency: Intraindividual change and variability. Psychology and Aging, 20, 623-633.

Rast, P. (2011). Verbal knowledge, working memory, and processing speed as predictors of verbal learning in older adults. Developmental Psychology, 47, 1490-1498.

Raven, J. C. (1958). Standard progressive matrices. Sets A, B, C, D and E. Oxford: Psychologist Press Ldt.

Raven, J. C. (1962). Advanced progressive matrices. Set II. Oxford: Psychologist Press Ldt.

Raven, J., Raven, J. C., \& Court, J. H. (1998). Manual for raven's progressive matrices and vocabulary scales. Section 5: The mill hill vocabulary scale. San Antonio, TX: Harcourt Assessment.

Redick, T. S., Shipstead, Z., Harrison, T. L., Hicks, K. L., Fried, D. E., Hambrick, D. Z., et al. (2013). No evidence of intelligence improvement after working memory training: A randomized, placebo-controlled study. Journal of Experimental Psychology: General, 142, 359-379.

Richmond, L. L., Morrison, A. B., Chein, J. M., \& Olson, I. R. (2011). Working memory training and transfer in older adults. Psychology and Aging, 26, 813-822.

Saczynski, J. S., Willis, S. L., \& Schaie, K. W. (2002). Strategy use in reasoning training with older adults. Aging, Neuropsychology and Cognition, 9, 48-60.

Salthouse, T. A., \& Babcock, R. L. (1991). Decomposing adult age differences in working memory. Developmental Psychology, 27, 763-776.

Schaie, K. W., \& Willis, S. L. (1986). Can decline in adult intellectual functioning be reversed? Developmental Psychology, 22, 223-232.

Schmiedek, F., Lövdén, M., \& Lindenberger, U. (2010). Hundred days of cognitive training enhance broad cognitive abilities in adulthood: Findings from the COGITO study. Frontiers in Aging Neuroscience, 2, 1-11.

Shing, Y. L., Brehmer, Y., \& Li, S.-C. (2008). Cognitive plasticity and training across the lifespan. In O.-S. Tan \& A. S.-H. Seng (Eds.), Cognitive modifiability in learning and assessment: International perspectives (pp. 59-82). Singapore: Thomson Learning.

Shipstead, Z., Redick, T. S., \& Engle, R. W. (2012). Is working memory training effective? Psychological Bulletin, 138, 628.

Spieler, D. H., Balota, D. A., \& Faust, M. E. (1996). Stroop performance in healthy younger and older adults and in individuals with dementia of the Alzheimer's type. Journal of Experimental Psychology, 22, 461-479.

Sternberg, R. J. (2008). Increasing fluid intelligence is possible after all. Proceedings of the National Academy of Sciences, 105, 6791-6792.

Stroop, J. R. (1935). Studies of interference in serial verbal reactions. Journal of Experimental Psychology, 18, 643-662.

Thorndike, E. L., \& Woodworth, R. S. (1901). The influence of improvement in one mental function upon the efficiency of other functions: III. Functions involving attention, observation and discrimination. Psychological Review, 8, 553-564.

Tisak, J., \& Meredith, W. (1990). Descriptive and associative developmental models. In A. V. Eye (Ed.), Statistical methods 
in longitudinal research (Vol. 2, pp. 387-406). Boston: Academic Press.

Voelkle, M. C. (2007). Latent growth curve modeling as an integrative approach to the analysis of change. Psychology Science, 49, 375.

Westerberg, H., \& Klingberg, T. (2007). Changes in cortical activity after training of working memory: a single-subject analysis. Physiology and Behavior, 92, 186-192.

Willis, S. L. (2001). Methodological issues in behavioral intervention research with the elderly. In K. W. Schaie \& J. E. Birren (Eds.), Handbook of the psychology of aging (5th ed., pp. 78-108). San Diego, CA: Academic Press.

Willis, S. L., Blieszner, R., \& Baltes, P. B. (1981). Intellectual training research in aging: Modification of performance on the fluid ability of figural relations. Journal of Educational Psychology, 73, 41-50.

Willis, S. L., Jay, G. M., Diehl, M., \& Marsiske, M. (1992). Longitudinal change and prediction of everyday task competence in the elderly. Research on aging, 14, 68-91.
Willis, S. L., \& Schaie, K. W. (2009). Cognitive training and plasticity: Theoretical perspective and methodological consequences. Restorative Neurology and Neuroscience, 27, 375-389.

Willis, S. L., Schaie, K. W., \& Martin, M. (2009). Cognitive plasticity. In V. L. Bengtson, N. P. D. Gans, \& M. Silverstein (Eds.), Handbook of theories of aging (pp. 295-322). New York: Springer.

Zelinski, E. M. (2012). Are strategies necessary to improve memory? Journal of Applied Research in Memory and Cognition, 1, $56-57$.

Zinke, K., Zeintl, M., Eschen, A., Herzog, C., \& Kliegel, M. (2012). Potentials and limits of plasticity induced by working memory training in old-old age. Gerontology, 58, 79-87.

Zinke, K., Zeintl, M., Rose, N. S., Putzmann, J., Pydde, A., and Kliegel, M. (2014). Working memory training and transfer in older adults: effects of age, baseline performance, and training gains. Developmental Psychology, 50, 304-315. 